\title{
A Clinical A udit of Pap Smear Test for Screening of Cervical Cancer
}

\author{
Tamrakar SR, Chawla CD \\ Department of Obstetrics and Gynecology, Dhulikhel Hospital-Kathmandu University Hospital, Dhulkhel, Kavre
}

\begin{abstract}
Aims: Cervical cancer is a major cause of morbidity and mortality in gynecology clients. It accounts for the most common cancer in women. A Papanicolaou (Pap) smear test (cervical cytology screening) is one of the best tests to screen for cervical cancer in its premaligant stage. The objective of this study is to find out the prevalence of abnormal Pap smear results and to determine the contributing factors for it.

Methods:The out patient clinic register was reviewed. Out-patients clinic register from 1 Jan 2008 to 31 Dec 2011showed that a total of 25511 gynecology clients were seen. In these four years duration, a total of 1506 Pap smear samples were taken which accounted for $5.9 \%$ of the total gynecology clients. The samples were collected only after proper counseling and consent from the clients who visited the clinic for various gynecology complaints. Assumed predictors of abnormal Pap smear results were examined through inferential way (Chi square test) using Software SPSS version 13.0 for Windows.
\end{abstract}

Results:The preliminary analysis showed the mean age was $37.57 \pm 10.72$ years (ranging from 18 to 81 years). Most of them were of Newar caste (28.7\%), with 3 children (37.6\%) and from Kavre District (66\%). Most of them (343 clients) were of age group 30 - 34 years whereas $15.8,10.8,3.1$ and $10.0 \%$ (clients were of $40-44,45-49,50-54$ and 55 above respectively. A total of 1062 samples were normal whereas 379 samples were suggestive of inflammatory and 39 samples were inadequate for evaluation. We had 22 samples suspious for malignancy and/or low grade squamous intraepithelial lesion (LSIL) and 4 frank malignant cases. This accounted for $1.7 \%$ of total Pap smear samples. These cases were scheduled for colposcopic guided biopsies and histologic evaluations. There was significant difference between the age groups and Pap smear results $(\mathrm{p}=0.003)$ and parity with Pap smear results $(\mathrm{p}=0.000$, highly significant). But there was no significant difference between caste and Pap smear results $(\mathrm{p}=0.166)$.

Conclusions:There is no doubt that Pap test is one of the best and easiest tests to screen for precancerous and cancerous cervical lesions. In order to have a high yield it has to be combined with other alternative tests like HPV testing and/or visual inspection with acetic acid (VIA) or Lugol's Iodine (VILI). Besides its use as screening tool, we can also evaluate for chronic cervicitis, sexually transmitted infection (STI), pelvic inflammatory disease (PID)and genital prolapse (if any) in same setting. Thus the community people will have broader benefits from the screening program.

Keywords: Cervical cancer, HPV testing, Pap smear, VIA, VILI

\section{INTRODUCTION}

Cervical cancer is a major cause of morbidity and mortality in gynecology clients. It is the leading cancer among women in developing countries like Nepal. Evaluation of screening performance for effective, feasible and affordable early detection and management methods is a public health priority. Five screening methods, naked eye visual inspection of the cervix after application of diluted acetic acid (VIA), of Lugol"s lodine (VILI) or with a magnifying device (VIAM), the Pap smear and human papilloma virus (HPV) testing with high-risk probe of the
Hybrid Capture-2 assay (HC2) are being used to screen and detect the cervical cancer in precancerous stage. ${ }^{1}$

Cytology is a simple and inexpensive diagnostic method and is therefore especially useful in areas with limited resources. Even though the Pap smear test alone does not have a high sensitivity and specificity, it is the most commonly used test in most screening programs. ${ }^{2}$ This clinical audit was done to find out the prevalence of abnormal Pap smear results and the contributing factors for it.

\section{CORRESPONDENCE}

Dr Suman Raj Tamrakar, MD

Assistant Professor

Department of Obstetrics and Gynecology,

Dhulikhel Hospital-Kathmandu University Hospital,

Dhulkhel, Kavre

Phone: 9741121546

Email: drsuman537@yahoo.com 


\section{METHODS}

The pap smear samples were collected after proper counseling and informed consent was taken from the clients visiting the clinic for various gynecology complaints. Assumed predictors of abnormal Pap smear results were examined through inferential way (Chi square test) using Software SPSS version 13.0 for Windows.

\section{RESULTS}

The out patient clinic register of Dhulikhel Hospital (DH) from 1 Jan 2008 to 31 Dec 2011 showed that a total of 25511 gynaecology clients had received services. In these four years duration,1506 Pap smear samples were taken which account for $5.9 \%$ of these clients.
A total of 1062 samples were normal whereas 379 samples were suggestive of inflammatory and 39 samples were inadequate for evaluation. We have got 22 samples suspicious for malignancy and/or LSIL and 4 frank malignant cases. These account for $1.7 \%$ of total Pap smear samples. These cases were scheduled further for colposcopic guided biopsies and histologic evaluations.

There was significant difference in Pap smear result according to the age group $(p=0.003)$ and parity $(p=0.000$, highly significant). But there was no significant difference in Pap smear result in different castes $(p=0.166)$.

Table 1. Comparison of Pap Smear results according to age group

\begin{tabular}{llllllll}
\hline Papsmear & Normal & Inflamm & LSIL & Suspi & Inadequate & +ve for malig & Total \\
\hline Age $\leq 24$ & $87(77.0 \%)$ & $22(19.5 \%)$ & $1(0.9 \%)$ & $1(0.9 \%)$ & $2(1.8 \%)$ & $0(0.0 \%)$ & 113 \\
$25-29$ & $155(74.2 \%)$ & $52(24.9 \%)$ & $0(0.0 \%)$ & $0(0.0 \%)$ & $2(1.0 \%)$ & $0(0.0 \%)$ & 209 \\
$30-34$ & $229(66.8 \%)$ & $101(29.4 \%)$ & $0(0.0 \%)$ & $1(0.3 \%)$ & $11(3.2 \%)$ & $1(0.3 \%)$ & 343 \\
$35-39$ & $181(73.9 \%)$ & $56(22.9 \%)$ & $1(0.4 \%)$ & $2(0.8 \%)$ & $5(2.0 \%)$ & $0(0.0 \%)$ & 245 \\
$40-44$ & $175(73.5 \%)$ & $49(20.6 \%)$ & $1(0.4 \%)$ & $3(1.3 \%)$ & $10(4.2 \%)$ & $0(0.0 \%)$ & 238 \\
$45-49$ & $115(71.0 \%)$ & $40(24.7 \%)$ & $1(0.6 \%)$ & $2(1.2 \%)$ & $3(1.9 \%)$ & $1(0.6 \%)$ & 162 \\
$50-54$ & $32(69.6 \%)$ & $12(26.1 \%)$ & $1(2.2 S 5 \%)$ & $1(2.2 \%)$ & $0(0.0 \%)$ & $0(0.0 \%)$ & 46 \\
$\geq 55$ & $88(58.7 \%)$ & $47(31.3 \%)$ & $0(0.0 \%)$ & $7(4.7 \%)$ & $6(4.0 \%)$ & $2(1.3 \%)$ & 150 \\
Total & 1062 & 379 & 5 & 17 & 39 & 4 & 1506 \\
\hline
\end{tabular}

Table 2. Comparison Pap Smear results according to parity

\begin{tabular}{llllllll}
\hline Papsmear & Normal & Inflamm & LSIL & Suspi & Inadequate & +ve for malig & Total \\
\hline Parity 0 & $13(92.9 \%)$ & $0(0.0 \%)$ & $0(0.0 \%)$ & $0(0.0 \%)$ & $1(7.1 \%)$ & $0(0.0 \%)$ & 14 \\
1 & $100(75.8 \%)$ & $30(22.7 \%)$ & $0(0.0 \%)$ & $1(0.8 \%)$ & $1(0.8 \%)$ & $0(0.0 \%)$ & 132 \\
2 & $353(72.8 \%)$ & $121(24.9 \%)$ & $1(0.2 \%)$ & $1(0.2 \%)$ & $9(1.9 \%)$ & $0(0.0 \%)$ & 485 \\
3 & $401(70.8 \%)$ & $139(24.6 \%)$ & $1(0.2 \%)$ & $5(0.9 \%)$ & $18(3.2 \%)$ & $2(0.4 \%)$ & 566 \\
4 & $117(67.2 \%)$ & $47(27.0 \%)$ & $2(1.1 \%)$ & $2(1.1 \%)$ & $6(3.4 \%)$ & $0(0.0 \%)$ & 174 \\
5 & $78(57.8 \%)$ & $42(31.1 \%)$ & $1(0.7 \%)$ & $8(5.9 \%)$ & $4(3.0 \%)$ & $2(1.5 \%)$ & 135 \\
Total & 1062 & 379 & 5 & 17 & 39 & 4 & 1506 \\
\hline
\end{tabular}

Table 3. Comparison of current study with previous clinical studies

\begin{tabular}{|c|c|c|}
\hline Author & $\begin{array}{l}\text { Sample } \\
\text { Size }\end{array}$ & Results \\
\hline Sherpa et al ${ }^{6}$ (2009) & $n=932$ & $3.6 \%$ abnormal pap smear \\
\hline $\begin{array}{l}\text { Dharbhadel } \\
\text { et al (2004) }\end{array}$ & $n=350$ & $0.57 \%$ positive pap smear \\
\hline $\operatorname{Pradhan}^{8}(2002)$ & $n=800$ & $4.8 \%$ abnormal pap smear \\
\hline Sarian et $\mathrm{al}^{9}(2005)$ & $\mathrm{n}=11834$ & $\begin{array}{l}2.2 \% \text { (LSIL threshold) } \\
1.1 \% \text { (HSIL threshold) }\end{array}$ \\
\hline $\begin{array}{l}\text { Sankaranarayanan } \\
\text { et al }{ }^{10}(2003)\end{array}$ & $n=4444$ & $3.4 \%$ \\
\hline Current Study & $n=1506$ & $\begin{array}{l}1.7 \% \text { premalignant and } \\
\text { malignant }\end{array}$ \\
\hline
\end{tabular}

\section{DISCUSSION}

Gynecological cancers are among the preventive cancers. Cervical cancer is the most common female genital tract malignancy among Nepalese women. Cervical cancer can be prevented and premalignant conditions can be detected before invasion by different tests. ${ }^{3}$

It was recommended that women who are negative on both tests (cytology and HPV DNA testing) do not require rescreening for 3 years. It is well established that on average it takes approximately 10 years for a CIN 2,3 lesion to progress to an invasive cancer (i.e. the transit time). ${ }^{4}$ 
No population-based estimates of cervical cancer incidence in Nepal exist, but WHO has estimated that the incidence rate is approximately 26-28 per 100000 women per year. Though the prevalence of cervical cancer in Nepal is not well documented, it is the most commonly reported malignancy among women in Nepal with approximately 2150 invasive cervical cancers and 1100 deaths annually. ${ }^{5}$

In developed countries, initiation and sustainability of cervical cytology programs involving the screening of sexually active women annually, or once in every 2-5 years, have resulted in a large decline (up to $80 \%$ ) in cervical cancer incidence and mortality over the last $40-50$ years. ${ }^{11,12}$

The WHO recommends that in developing countries, women aged 18-69 years should be screened for cervical cancer every 3 years. In Nepal only $2.4 \%$ of women in this category currently meet this standard. ${ }^{13}$ There was significant difference in Pap smear results between different age group $(p=0.003)$. As the age of the clients advances, LSIL, suspicious lesions and frankly malignant cases were seen more. For example in the age group $\geq 55$ years seven suspected lesions and two malignant cases were seen.

Epidemiological studies conducted during the last 40 years have consistently indicated that cervical cancer risk is strongly influenced by measures of sexual activity: number of sexual partners, age of first intercourse and sexual behavior of the woman's male partners. ${ }^{14,15}$

History of sexually transmitted diseases increases the risk of developing cervical cancer. Tobacco smoking is a well-known risk factor for cervical cancer.16A direct carcinogenic action of cigarette smoking on the cervix has been proposed since nicotine metabolites can be found in the cervical mucus of women who smoke.

Though smoking habit of the clients was not assessed in this study, smoking habit in female populations in Nepal was quite common. The number of live births is a consistent risk factor for cervical cancer. Previous studies done by Brinton have shown that there is a linear trend in the association between parity and risk. ${ }^{17}$ In this study, there was significant difference between parity with abnormal pap smear result ( $p=0.000$, highly significant). As the parity of the clients advances, LSIL, suspected lesions and positive for malignant cases were seen more. Notably more LSIL, suspected lesions and malignant cases were seen in para $\geq 3$.

Among the general population, the overall prevalence of HPV was $8.6 \%$ (6.1\% for high-risk types). Approximately $80 \%$ of cervical cancer in Nepal is theoretically preventable by HPV $16 / 18$ vaccines. 6 Though many of the studies included in one meta-analysis are quite old and were conducted before the introduction of liquid-based cytology or the use of cyto-brushes, the meta-analysis (which reviewed 94 screening studies) found that the sensitivity of cervical cytology ranged from $30 \%$ to $87 \% .^{2}$

The cytology result allows HPV DNA positive women to be triaged into 2 groups, those requiring colposcopy and those who can simply be followed-up. Liquid based cytology enables the use of supplementary methods in the diagnosis and prognosis of cervical lesions.18 Liquid based cytology was significantly more sensitive than conventional cervical cytology for detecting CIN $2 .{ }^{4}$

A prospective study ( $n=350$ ) conducted by Dhaubhadel et al found that VIA as a screening test for cervical neoplasia did not miss any lesion detected by Pap smear and confirmed by cervical biopsy. ${ }^{7}$

Qureshi et al evaluated the effectiveness of VIA and VILI compared to Pap smear as screening methods for carcinoma of the cervix, the results were as follows: Pap smear test (sensitivity $20.83 \%$, specificity $98.38 \%$ ), VIA $(55.5 \%, 71.39 \%)$, and VILI (86.84\%, 48.93\%). They concluded that VIA and VILI are less specific in comparison to the Pap smear but they are more sensitive in detecting pre-invasive lesions. Hence VIA and VILI can be used as cervical cancer screening tools in low-resource settings. ${ }^{10,19}$

However, the Latin American screening (LAMS) study ( $n=11834$ ) failed to reproduce the performance figures obtained with VIA and VILI (as stand-alone tests) in some other settings, where the prevalence of cervical disease was higher. A combined use of VIA or VILI with the Pap test or HC2 allowed specific detection of cervical abnormalities.9 The largest ever study $(n=58000)$ in the developing countries performed by Arbyn et al found VIA had a sensitivity of $79 \%$ and $83 \%$, and a specificity of $85 \%$ and $84 \%$ for the outcomes CIN2 and CIN 3, respectively. VILI was on average $10 \%$ more sensitive and equally specific. VIAM showed similar results as VIA. The pap smear showed lowest sensitivity. The $\mathrm{HC} 2$-assay showed sensitivity for CIN2 of $62 \%$ and a specificity of $94 \%$. Results of visual tests and colposcopy were highly correlated. ${ }^{1}$

In another study, most of the high-risk HPV DNA positive women who subsequently developed biopsy-confirmed CIN 3 were infected with HPV 16 or HPV 18.20 Hence women with specific high-risk types of HPV such as HPV 16 , $18,33,45$ or 31 (the 5 most common HPV types found in cervical cancers) would be referred to colposcopy whereas those with other high-risk types of HPV would be followedup in 12 months with a repeat HPV DNA test. ${ }^{4}$

More recent research studies continue to report that the sensitivity of a single cervical cytology test is relatively low hence an alternative strategy that appears even more promising to screen using HPV DNA testing alone and use a combination of both reflex cytology and HPV genotyping. ${ }^{4}$ 


\section{CONCLUSIONS}

Cervical cancer is a relatively neglected disease in terms of advocacy, screening and prevention from professional or public health organizations. There is no doubt that Pap test is one of the best and easiest tests to detect precancerous cervical lesions. In order to have a high yield it has to be combined with other alternative tests like HPV testing and/ or visual screening with acetic acid (VIA) or Lugol's lodine (VILI).

\section{REFERENCES}

1. Arbyn M, Sankaranarayanan R, Muwonge $R$, Keita $N$, Dolo A, Mbalawa CG et al. Pooled analysis of the accuracy of five cervical cancer screening tests assessed in eleven studies in Africa and India. Int J Cancer. 2008;123(1):153-60.

2. Nanda K, McCrory DC, Myers ER, Bastian LA, Hasselblad V, Hickey JD et al. Accuracy of the Papanicolaou test in screening for and follow-up of cervical cytologic abnormalities: a systematic review. Ann Intern Med 2000;132:810-9.

3. Dhakal S. Oncoprevention in gynecology. JNMA J Nepal Med Assoc. 2010;49(178):167-73.

4. Wright TC. Cervical cancer screening in the 21st century: is it time to retire the PAP smear? Clin Obstet Gynecol. 2007;50(2):313-23.

5. Sankaranarayanan R, Bhatla N, Gravitt PE, Basu P, Esmy PO, Ashrafunnessa KS et al. Human papillomavirus infection and cervica cancer prevention in India, Bangladesh, Sri Lanka and Nepal. Vaccine. 2008;26(Suppl 12):M43-52

6. Sherpa AT, Clifford GM, Vaccarella S, Shrestha S, Nygård M, Karki BS et al. Human papillomavirus infection in women with and withou cervical cancer in Nepal. Cancer Causes Control. 2010;21(3):323-30.

7. Dhaubhadel P, Vaidya A, Choudhary P. Early detection of precursors of cervical cancer with cervical cytology and visual inspection of cervix with acetic acid. JNMA J Nepal Med Assoc. 2008;47(170):71-6.

8. Pradhan P. Prevention of carcinoma cervix: role of Pap smea screening. Nepal Med Coll J. 2003;5(2):82-6.

9. Sarian LO, Derchain SF, Naud P, Roteli-Martins C, Longatto-Filho A Tatti $S$ et al. Evaluation of visual inspection with acetic acid (VIA) Lugol's iodine (VILI), cervical cytology and HPV testing as cervical screening tools in Latin America. J Med Screen. 2005;12(3):142-9.

10. Sankaranarayanan R, Wesley R, Thara S, Dhakad N, Chandralekha $B$, Sebastian $P$ et al. Test characteristics of visual inspection with $4 \%$ acetic acid (VIA) and Lugol's iodine (VILI) in cervical cancer screening in Kerala, India. Int J Cancer. 2003;106(3):404-8.
11. Hamaka M, Chamberlain J, Day NE, Miller AB, Prorok PC. Evaluation of screening programmes for gynaecological cancer. Br J Cancer 1985;52(4):669-73.

12. Gustafsson L, Ponten J, Zack M, Adami HO. International incidence rates of invasive cervical cancer after introduction of cytological screening. Cancer Causes Control 1997;8(5):755-63.

13. WHO/ICO HPV information centre, summary report update 2010 .

14. Schiffman MH, Brinton LA. The epidemiology of cervical carcinogenesis. Cancer. 1995;76(10 Supp):1888-901.

15. Franco EL. Epidemiolgy of uterine cancers. In: Meisels A, Mortin C editors. Cytopathology of the uterus. 2nd ed. Chicago: American Society of Clinical pathologists; 1997.p.301-24.

16. Winkelstein W. Smoking and cervical cancer-current status: a review. Am J Epidemiol. 1990;13(6)1:945-57.

17. Brinton LA, Hamman RF, Huggins GR, Lehman HF, Levine RS, Mallin $\mathrm{K}$ et al. Sexual and reproductive risk factors for invasive squamous cell cervical cancer. J Natl Cancer Inst. 1987;79(1):23-30.

18. Juric D, Mahovlic V, Rajhvajn S, Ovanin-Rakic A, Skopljanac-Macina L, Barisic $A$ et al. Liquid based cytology-new possibilities in the diagnosis of cervical lesions. Coll Anthropol. 2010;34(1):19-24.

19. Qureshi S, Das V, Zahra F. Evaluation of visual inspection with acetic acid and Lugol's iodine as cervical cancer screening tools in a lowresource setting. Trop Doct. 2010;40(1):9-12.

20. Khan MJ, Castle PE, Lorincz AT, Wacholder S, Sherman M, Scott DR et al. The elevated 10-year risk of cervical precancer and cancer in women with human papillomavirus (HPV) type 16 or 18 and the possible utility of type-specific HPV testing in clinical practice. J Natl Cancer Inst. 2005; 97(14):1072-9. 